\title{
Diabetes Therapy Podcast Collection: Language Matters in Diabetes
}

Sanjay Kalra · Partha Kar

Received: April 16, 2021 / Accepted: April 24, 2021 / Published online: May 28, 2021

(C) The Author(s) 2021

\section{DIGITAL FEATURES}

This article is published with digital features, including a podcast video and audio file, to facilitate understanding of the article. To view digital features for this article go to https://doi. org/10.6084/m9.figshare.14459949.

\section{PODCAST TRANSCRIPT}

Victoria Glasson (VG): Managing Editor of Diabetes Therapy

Sanjay Kalra (SK): Department of Endocrinology, Bharti Hospital, Karnal, Haryana, India

Partha Kar (PK): Portsmouth Hospitals NHS Trust, Portsmouth, UK

VG: Hello and welcome to the Adis podcast series. You are listening to a podcast on diabetes therapy. Today we are discussing language in

Supplementary Information The online version contains supplementary material available at https:// doi.org/10.1007/s13300-021-01069-z.

S. Kalra $(\bowtie)$

Department of Endocrinology, Bharti Hospital,

Karnal, Haryana, India

e-mail: brideknl@gmail.com

P. Kar

Portsmouth Hospitals NHS Trust, Portsmouth, UK diabetes management, and joining me today is Dr. Sanjay Kalra, endocrinologist at Bharti Hospital, and Professor Partha Kar, Consultant in Diabetes and Endocrinology at Portsmouth Hospital's NHS Trust. Thank you so much for joining us today, Sanjay and Partha.

SK: Thank you. Thank you for the invite.

PK: Thank you.

VG: You're going to discuss the importance of language in diabetes management, and this is a really interesting and developing topic. I think you both agree, the relationship between doctors and patients is a really important one, and we've come a long way in recent years, especially with the Language Matters movement. There is still a lot of communication and building relationships between health care professionals and between patients, and engaging patients to maximize the outcomes we can help with their care.

That's our topic for today, and Sanjay, would you like to get us started?

SK: Sure, Victoria. Hi, everybody. My name is Sanjay Kalra. I'm an endocrinologist, and I work in a city called Karnal in northern India. I've been in endocrinology now for more than two decades. Each day is a new day. I get to meet new patients. I get to speak and converse with new patients and their family members. And I get to learn every single day.

It's a great pleasure to be with Partha. Partha, would you like to introduce yourself? What work do you do? 
PK: Thanks very much. So my name is Partha, as you mentioned, and I'm a consultant in diabetes. I work in Portsmouth which is a city or town near the sea in the United Kingdom or England. And obviously my background is I come from India as well and have been here since I started my training. Very much looking into diabetes work here across the community, type 1 and type 2 diabetes, and other works doing national roles, trying to sort of increase technology uptake and Language Matters, et cetera, which I'm sure we'll talk about later on.

SK: So Partha, every day in your practice you meet with the people who live with diabetes, and you meet with their family members, their close friends as well.

PK: Absolutely. It's part and parcel of what I do. It's very much every day.

SK: Do these people come to you only for glucose control, or do they have other needs as well?

Let's imagine the last person whom you met who was newly diagnosed with type 1 diabetes.

PK: So I think it depends as to the clinic that you're running. So some of it is new. Some of it is follow-up. And I think it's fair to say that the new ones who come, come [to us] with specific problems, whether it's a diabetes-related glucose problem or it's an endocrine problem, because I do pituitary disease as well, management. That would be a specific reason for them coming.

I think what you do tend to find is that as you get to know the patients or they become part of the, you're doing their chronic disease management, their presentations, all they'd ask, is wider. It's not just about the diabetes or just about their pituitary problem. It's much more wider. They might have other issues like psychological problems, mental health issues, et cetera. So lots of issues wider than just the glucose or that particular topic.

SK: Are they sometimes sad or afraid, or are they angry? What are the kind of emotions that you see? And let's for the time being, let's talk about people who have type 1 diabetes newly diagnosed.

PK: So I think in the initial phases what you see is [that] people have different emotion ranges. And it's the same thing; everybody's a human being so the challenge of trying to deal with your diabetes when it is newly diagnosed, there's a degree of frustration around it as to why they've got it. You go through the phases of denial, and anger, et cetera. So there's that emotion side. Then there's also wider frustrations that may be just with their lives, or their living conditions, or whatever they have. So you will have a gamut of emotions. You'll also have, for example, in present times, you'll have patients who come and see you who are feeling in a much more sort of comfortable space. Much happier from that point of view. So you have got a complete wide range of emotions that you have to deal with as well.

SK: Is this part and parcel of our work, handling these emotions, channelling them into the right path so that they can have better health? Or can we abdicate this responsibility as diabetes care professionals? Can we abdicate it to somebody else?

PK: My personal view has always been that as a doctor you're very much the guide along the journey. Your job isn't just to look at the glucose levels and walk away. I think you've got a wider role because [with] some clinic visits and some appointments the patient may not be wanting to speak at all about their glucose. They might want to talk about something else completely different.

I think it's part of that relationship building that the person feels here they're comfortable to have that conversation with you. Because at the end of the day, if you in some way can help in improving their quality of life, or in simple ways just having a friendly ear to listen to, you in turn may be improving the diabetes control just by doing that. I don't think our job is only to do... what traditionally would be called just the doctor role or the medical role. I think, is a bit wider, especially when you're dealing with long-term conditions like diabetes.

SK: What you said just now is really important, Partha. Could you repeat that? What you said was you can help improve their diabetes control by doing just that. By doing just what? Can you repeat that again for everybody?

PK: I think it's just a question of being a bit more of a human being and having a listening ear. It's something like sometimes you can't 
solve everybody's problem in life. And this is the approach we normally take with our friends and family. If they come to you with a particular problem, it's not always that they're expecting you to solve it for you. I think sometimes people just need to hear that there is a supportive person who will listen to their issues at hand. I think that's what also the role of the doctor is.

If a person is really worried about how their home situation is, then that's impacting on their diabetes. So if you can give some advice around it, if you can try and help as much as possible, that in itself may rest their mind to an extent that they might be able to look after their diabetes better. I think small things like that do matter, and I think our role needs to be bigger from that perspective rather than just being gluco-centric, so to speak, or glucose control motivated.

SK: So we're talking today about the importance of language in diabetes care. And what Partha has just now reinforced is that listening is an important part of language. You have to have a listening ear; the same way someone would use a stethoscope or maybe use an ultrasound machine to see what's going on in the patient's body. You can use your ears as a part of treatment. And the fact that you are listening, that itself is a treatment. That's what Partha said. This is actually proven by evidence as well. If you listen properly to your patient, if you build a bond with the patient, it helps both parties. Number one, the patient feels happy. The patient feels relaxed. Number two, if you listen with both ears open you can actually get clues as to why the patient has developed diabetes, why the patient has developed uncontrolled diabetes, and perhaps what you can do to mitigate the challenges that he or she is facing.

Partha, could you give us an example from your clinic? You actually listened carefully, and that is why you were able to come to a diagnosis. And maybe if you could give an example of when you made a mistake; you didn't listen properly in the first meeting, and it took a couple of opening visits for you to sort out your patient's problem just because you didn't listen properly the first time.
PK: Yeah, and I can give you an example; actually that's a very good question because I can give you an example of one person in which I think both sides I can give you the examples of not listening. So there was this young gentleman who used to come into hospital regularly with DKA [diabetic ketoacidosis]. It was the usual thing, the belief you know where, oh, it's just a 17-, 18-year-old, probably not looking after himself. You know, just going out and partying and doing the usual stuff the teenagers do, which is why he's coming into hospital with diabetic ketoacidosis, et cetera.

So I think the first-I remember going into this consultation with a very preformed opinion about this young gentleman and saying that well that must be it really. So the advice is very simple, you know, you really should take your insulin regularly, and you know, you just stop sort of-and what was interesting that in the looking back, he was obviously bit taken aback by the whole presumptions made by somebody like me who he had never met in his life. The reaction from his end was not to have that conversation anymore. So it was a very sort of very quiet conversation from his end. He didn't say much. I made the presumption that, well it's probably because he's just being a teenager, doesn't want to talk.

Over the subsequent visits, what I realized that there was something much more simpler than that. It was [that] this gentleman, due to a family breakdown, was actually living or given a home by the local council here to live because he was homeless. But the problem was the council had given him a house which didn't have any fridge. So there was nowhere he could keep his insulin, or wherever he kept his insulin they were basically-even if he was injecting they just weren't working. It was something very simple along those lines while the presumption was-so to sort that out, it was calling on the council, and the council were really helpful, and what we said is that you really need to get the gentleman a fridge because he's on something like insulin, which is lifesaving, that needs to be in a fridge, et cetera. So it took about $20 \mathrm{~min}$ on the phone call to have that sorted out, but it was quite interesting how it took me a few visits to got caught on to that. Some of it 
was because over the course of time I said, well let's listen to what he's trying to say, then we talked a little bit more and those things came out.

So that to me is a very good example whereby just focusing on the glucose and not giving time to the person has been the wrong approach to take. When you're trying to build that-as you said, you build a better relationship as time goes, and then you find out more deeply about simple issues you can tackle and thereby improve his diabetes in return as well.

SK: Thanks, Partha. So so far we've been speaking of listening. Now Partha introduced a newer dimension, another dimension, and that was speaking with this gentleman.

So Partha, let's say you and I are having a conversation. Victoria is conversing with us. How would you want to be spoken [to]?

PK: I think it's the same principle when you speak to anybody in life. What you don't want to have is people being rude. You don't want people to be very off in the sense that they're very dismissive of your views. And you don't want people to interrupt what you're trying to say constantly. So I think it's a simple philosophy of how we would interact with each other as human beings. If there was a stranger in the world, we wouldn't just jump in, make presumptions, cut them off, be rude. There's no reason I would expect that from you and Victoria either. And that's what I would expect in a conversation. I suspect that that's the ethos of what we are trying to do with our clinical consultation skills going forward.

VG: You made a really great statement there, Partha, saying about presumptions. I think quite often it can be presumed that patients aren't fully aware of their diagnosis, of their disease, and that really physicians can sometimes forget to listen to patients because they think that they are not informed. I think that's a really great point that patients, now, they are engaging. They are wanting to find out information about their disease. They are very much informed, and so taking that time to engage with your patient and to listen to what they have to say, as you both mentioned before, that can really help to give you clues as to why they are uncontrolled or why a particular therapy isn't working well with them. I think that presumption can often bring up more barriers between a patient and physician relationship.

PK: Absolutely.

SK: Thanks, Victoria. So Partha, what we were discussing just now, is this true for both type 1 , and type 2 diabetes, and maybe also for gestational diabetes?

PK: I think it's true for any chronic disease, if I'm honest. To be honest, I think it's true for any consultation we do, even if you're doing orthopedics, or any other specialty. I think having the basic understanding of how to converse with people should not be something that we as doctors should lose. You know, the basic principles of not making presumptions, not being rude, we wouldn't do that with our friends and family. There's no reason to thereby do it in a clinical setting either in my book.

SK: Now conversing effectively and efficiently should be simple. It should come automatically naturally to all of us, but let's try to make it simpler for our audience. Can you give us a few examples, Partha? Let's take maybe a lady with gestational diabetes mellitus. Would you like to give an example of how not to speak with her? And then after that, once you've done the wrong language example, then talk about how actually to speak with her.

PK: So here we go. I mean, if you give an example-let's start with example as you said of what not to get right. So let's say this lady comes in, and let's say she's slightly overweight, and the diabetes.

And you start off by saying-so she starts off by saying, what do you think I've got? Why do I have diabetes? And the initial line tends to be, let's say you start off with saying, well that's probably because you carry too much weight. You know, if you looked after yourself a bit better then it may not have happened. So that's the starting point of how to get it completely wrong.

On the other hand, I think the presumption in that statement is that we don't know anything about this lady's background. Right? We don't know what deprivation she has got, what the home situation is, whether she's got any background hormonal problems. What are all the issues? We know nothing about it. We have 
made that presumption. A much more easy way to do that would be, I would say, to start off by saying so what do you understand about it? Because as Victoria said, it's a folly to presume that patients haven't read up a little bit or quite a fair bit about what they think they have. They may not have good sources about it, they may have good sources, we don't know. But I think a starting point would be, so what do you understand about what you've got? And how can I help you? What exactly are you worried about where you are, because you will have that worry then built in whereby I've got gestational diabetes. What does it mean for my baby? What is going to happen? All of those. It's about addressing the concerns so that she feels comfortable and much more in a better space about controlling or looking after her own diabetes. So that's an example I could probably give.

SK: Yeah. "How can I help you?" is a very nice starting point for all of us. So let's say you're new in practice or you don't know how to get the hang of language in your clinical practice in your career. Just begin with a smile and begin with "how can I help you?" That's a very simple way of getting the conversation on the right track. So we've spoken now about listening. We've also spoken about speaking. And there's a term known as words of comfort. There's another term known as diabetes therapy by the ear. So Partha, diabetes therapy by the ear, what does this mean? Does it mean insulin drops given through the ear?

PK: No, I think it's very much about your skills of listening. You're basically using all your senses in the appropriate way. I think that's what it's alludes to. It's a question of-and I think me and you, Sanjay, have spoken about this in the past, I think we miss out the simple things of what we can pick up just by keeping sometimes quiet in clinic rather than having to always feel the need to speak. Sometimes it's important to also keep quiet and make your ear work. Listen in what is being said, you might pick up lots of information hints with might help you in your own management as far as diabetes control is concerned.

SK: Thanks. Partha, you're a global leader in this movement called Language Matters. Can you tell us what Language Matters means?
PK: It's a very simple concept based on what we have just actually discussed, Sanjay. I mean it's the same thing which we have said, don't jump in. It's about what words we use. I think a lot of discussion tends to be hovering around, oh should we call somebody a diabetic or somebody with diabetes? That is actually not the concept of Language Matters. Language Matters is very much about, as you said, listening, having that sense of not jumping into presumptions, and talking to somebody who's got diabetes in front of you just as you would do to a colleague, with respect, with kindness, without the presumptions, with time to also listen and not interrupt them. I think it is just a conversation as we would do with any other normal human being. You could argue that is that something that doctors need to learn about? Is that something that we should know naturally? A lot of feedback all across the globe tells you that people with diabetes say that that doesn't happen. For example, the most important feedback I had when I was developing this piece of work in the UK, and thankfully it's been now in different parts of India as well, is the feedback that we got from a lot of people with diabetes was that the first question they had from their clinician when they met them was not "how are you?", it was more "how is your diabetes"? The subtle change makes a big difference. "How are you?" makes you feel much more sort of welcome; makes you understand or believe that the clinician in front of you is interested in you as a person. Well if your opening gambit is "how is your HbA1c?" or "how is your diabetes?", I think it just says that all I'm interested in is in your glucose levels, nothing else. I think the subtle little changes, and that's why the documents have been created as guides, there's obviously a version that we did in the UK, but with kind help from yourself we've got Indian versions for type 1 diabetes, now type 2 diabetes. We've got different languages going as well. It's just guides for colleagues to see what they can do to learn from that.

SK: You spoke about Language Matters in India. Can you tell us if we have translations of Language Matters in different languages? 
PK: Yes, we do. What we do have in India, we started off the journey by working with some type 1 diabetes patient groups, and they created the first version. I know we've done in English and Hindi. And subsequently there is a type 2 diabetes version, and I do know that there are other versions which are out. For example, there is a Tamil version I've seen. It's now being spread to other countries as well.

So the idea is to basically not just translate it. The idea is to have that in local language versions but with the same concept. So it's out there. Different national diabetes organizations have used it on their platforms, and it's just encouraging people to look at it and see if there's something just which might slightly change their practice so to speak.

SK: Thanks. Let's dissect this sentence that you used just now. You said it's not just a translation. It's a local version. Let's talk about individualizing care in diabetes, the same we talk of person-centered management. Should we have person-centered communication as well, and can you give a few examples from your clinic? You work in a multi-ethnic country.

PK: So I think if you talk through local variation the way you would, let's say in our country or in the United Kingdom that we are, and it's probably applicable to anybody who's even in India, because I think the approach you would take to somebody who comes from an Indian background and the approach you would take to somebody who comes from let's say a very pure English background or somebody comes from an African background has got to be different because the cultural needs are different. For example, if you say to somebody who comes from the Indian subcontinent that you know what, you really need to cut down your carbohydrates, and thereby you should not have rice, roti, or chapati, or anything. The person straightaway is starting to think, well, what am I supposed to have then? While inappropriate advice in an English person would be very different. I think having the nuances of differences in your head and also being aware of cultural relevance as of how you are speaking to people, in what aspect, what way, I think they're all very, very different. I think we need to be much more, as I said, you know appreciative of other people, their cultures, and understanding and have those tweaks as we go along.

SK: That's very well said, Partha. I think for our audience in case you're not sure, you do not always have to be culturally competent. None of us can know about all the cultures and all the linguistic groups in the world. But you can be culturally sensitive. Could you give us an example of this, Partha and Victoria both, being culturally sensitive even if you're not culturally competent.

PK: So I think culturally sensitive is a very simple example I can give you-and I can give you a personal example of being culturally sensitive. It would be, for example, you know seeing somebody who I remember came from a very, very traditional Hindu background. Extremely traditional. And I think there is the awareness that you are having a conversation with somebody which may not be in the same casual narrative because they come from a background where they believe, rightly, wrongly, whatever, that's a different issue altogether, about the hierarchy, how it needs to be done. There needs to be a different level of interaction and respect towards that. It would be fundamentally different from somebody who's 21 and who comes from pure English background. So I think culturally sensitive is being aware of those, aware of those different areas that you need to slightly change your style as regards how you interact with people. How you interact with somebody who is 21 , Caucasian is a bit different from somebody you're interacting with who is 72 and comes from a traditional Hindu family. I think those are the little things you need to be sensitive about rather being aware of every single thing.

SK: Thanks. Victoria, your take on this?

VG: I agree with Partha. It's about being aware. There is no one size fits all and so it's about thinking how would be best to interact with that person? Making small changes to best interact and engage with them rather than just treating everyone the same.

SK: Speaking from a diabetes care perspective, fasting and feasting are very important aspects of many people's lives. So if you're a 
diabetes care professional, do take time to ask your patient, do you fast? Do you feast? The fasts that you observe, are they religious? Are they cultural? Are they mandatory? Or do you do them just because you feel like doing it? And then this will also influence the kind of treatment that you offer. Partha, could you give an example of this from a UK perspective, again multi-ethnic?

PK: I think I mean I always give the example, when you say-I think that food is a very good example of that, isn't it? I mean that's what I find when you look at it. And I think it had been something which has been a learning point for me about-and when I say food, I'm not just talking about types of food. I'm talking about timings of food, for example. For example, there's a big thing about we have got plenty amount of Filipino population who like to have amounts of rice during certain parts of the day. I remember our dietitian really struggling with that concept. How do they have rice at lunch and dinner? So they kept on giving them advice, you should stop doing that. And the person just used to go like, OK, all right. And never did that because they never thought about any other life but that. So that's a good example of how you are trying to change somebody's lifestyle based on your belief, but at the same time it is not going to change anything unless you're aware of that, if that makes sense. So that's a good example for me about how you need to be aware of different areas, and I think that's the conversation. If you're saying if they're going like-and having that ability, or more importantly not sending that vibe that the person can't really challenge you back or ask you, um, sorry, but I can't do that. They need to have that relation with you to say that. If they're worried, they're afraid that they can't do that, then straightaway that breaks down, if that makes sense. So I think that's an example whereby all of it comes together, you know the building of relationship, the building of trust where people can be comfortable about saying that I don't understand this and go from there.

SK: You're right. Some best practices to tackle the situation which Partha just spoke about. The dietitian could have said, let's make a beginning by reducing the portion size. Or she could have said, OK, I understand that you need rice, but let's try to bring down the glycemic index by perhaps taking lots of salad or lots of beans before eating the rice. So this is a middle path that you can follow. The more you do this, the more information you will get from your patients. Your patients themselves will tell you, there are 33 different recipes for rice, these are the recipes where the glycemic load and the glycemic index is higher, these are the recipes where the glycemic load and index can be reduced. You get new information. On paper you were giving a consultation to your patient, but practically you ended up learning from your patient, and that's the way to go in a diabetes practice.

So Victoria, our topic for today was language and diabetes. Do you feel Partha has done a good job? How is his command of a language?

VG: I think excellent. Really great insights. Really. Which have come from your experience, Partha, as well. You've had some great examples in how to use language to better yourself as a physician but then to also really to gain that trust and build that relationship with your patients.

SK: I have been in endocrinology now for more than two decades, and to be honest, Victoria and Partha, this is what keeps me going. Language and-I will not shy away from saying that this is my biggest challenge. I still do make counselling mistakes. I make mistakes while listening, while speaking, while practicing diabetes therapy by the ear. I don't do it purposely, it just happens every now and then.

I feel very sad when this happens, and I try not to make the same mistake again. The number of mistakes I make, the number of errors I commit, has gone down markedly. I am trying to become a better listener and in the process a better diabetes care professional.

VG: Thank you, Sanjay. I think that really shows the importance of why I've recorded the podcast today, because language and the way to speak to patients is something that is always evolving, is something we can continuously learn about. If it's OK, I've just got a really quick question for the both of you. Sanjay and Partha, this year marks 100 years of insulin, which is an amazing celebration. We've certainly come a 
very long way in the care of diabetes since then. What are you both most excited for in the future of type 1 and type 2 diabetes care?

SK: I am excited because things are getting better and better. We have better diagnostic tools. We have much better monitoring tools now. We can monitor our patients' glucose levels and profile in a much easier in a more effective manner. We have new medication coming up. In type 2 diabetes, we have semaglutide, for example, oral as well as subcutaneous. We also see that the therapeutic space of diabetes and the therapeutic space of obesity are beginning to overlap each other. In the next year hopefully we should have approval for $2.4 \mathrm{mg}$ semaglutide which will be approved for weight loss, while the lower doses are going to be used for diabetes. Another place where we have overlap is in the field of SGLT2 inhibitors like empagliflozin and dapagliflozin. So the term that we use is endocrine exaptation. Drugs that were originally created for an endocrine indication for type 2 diabetes are being exapted or adapted for use in non-diabetic conditions like chronic kidney disease and heart failure. This is something exciting.

In type 1 diabetes we do not expect new insulins in the near future, but we do expect better delivery devices. The quality of insulin pumps that our children use, that is improving. And we should be able to close the loop, so as to say, in a more efficient manner in the next few years.

PK: From my point of view, I think there's two or three areas. Type 2 diabetes is going to go through a very exciting phase. You've got prevention. You've got reversal. All of that side of things, which is extremely exciting. And you also have all these new explosion of drugs with end organ improvement of outcomes, which is extremely exciting space to be in. And type 1 diabetes, I would just echo what you know Sanjay just mentioned. Closed loop is the future, and I think that's where this is all heading.

So all in all, I think it's quite a strong positive future for diabetes care. And I think professionals all around the world are excited, and so they should be.
VG: Thank you so much, Partha and to Sanjay, for talking with us today to discussing language and diabetes. And we really hope this has been of interest to all of our listeners.

SK: Thank you, Victoria. Thank you, Partha.

PK: Thank you very much. Thank you.

You can listen to more podcasts by subscribing to Adis Rapid+ podcast with your preferred podcast provider, or by visiting the website. A full list of declarations, including funding and author disclosure statements, can also be found on the journal website.

\section{ACKNOWLEDGEMENTS}

Funding. No Rapid Service Fee was received by the journal for the publication of this article.

Authorship. All named authors meet the International Committee of Medical Journal Editors (ICMJE) criteria for authorship for this article, take responsibility for the integrity of the work as a whole, and have given their approval for this version to be published.

Disclosures. Sanjay Kalra and Partha Kar have nothing to disclose.

Compliance with Ethics Guidelines. This article does not contain any new studies with human participants or animals performed by any of the authors.

Peer Review. Please note, contrary to the journal's standard single-blind peer review process, as a podcast this article underwent review by a member of the journal's Editorial Board.

Open Access. This article is licensed under a Creative Commons Attribution-NonCommercial 4.0 International License, which permits any non-commercial use, sharing, adaptation, distribution and reproduction in any medium or format, as long as you give appropriate credit to the original author(s) and the source, provide a link to the Creative Commons licence, and indicate if changes were made. The images or other third party material in this article are 
included in the article's Creative Commons licence, unless indicated otherwise in a credit line to the material. If material is not included in the article's Creative Commons licence and your intended use is not permitted by statutory regulation or exceeds the permitted use, you will need to obtain permission directly from the copyright holder. To view a copy of this licence, visit http://creativecommons.org/licenses/bync/4.0/. 